\title{
Legitimacy Accounts no Debate sobre a Reforma dos Tribunais de Contas Brasileiros
}

\section{Legitimacy Accounts in the Debate about the Reform of Brazilian Courts of Accounts} \\ Bruno Batista de Carvalho Luz ${ }^{1}$ \\ (D) https://orcid.org/0000-0002-0066-0995 \\ Marcos de Moraes Sousa ${ }^{2}$ \\ https://orcid.org/0000-0002-0901-0550 \\ Edson Ronaldo Guarido Filho ${ }^{3}$ \\ https://orcid.org/0000-0001-7905-1596
}

Universidade de Brasília, Programa de Mestrado e Doutorado Acadêmico em Administração, Brasília, DF, Brasil; Universidade Federal de Goiás, Programa de Mestrado e Doutorado Acadêmico em Administração, Goiânia, GO, Brasil ${ }^{1}$

Instituto Federal Goiano, Ceres, GO, Brasil; Universidade Federal de Goiás, Programa de Mestrado e DoutoradoAcadêmico em Administração, Goiânia, GO, Brasil ${ }^{2}$

Universidade Positivo, Programa de Mestrado e Doutorado em Administração, Curitiba, PR, Brasil, Universidade Federal do Paraná, Departamento de Ciência e Gestão da Informação, Curitiba, PR, Brasil ${ }^{3}$ 


\title{
Resumo
}

O objetivo desta pesquisa foi investigar o processo político-cultural relacionado ao debate em torno da reforma dos Tribunais de Contas brasileiros (TCs), organizações de aplicação da lei responsáveis pelo controle de recursos públicos. A pesquisa centrou-se em analisar como legitimacy accounts conduzidos por diferentes categorias de atores se manifestaram no debate acerca da reforma dos TCs brasileiros no período de 2000 a 2017 . Foram coletados dados de fontes documentais como discursos parlamentares, audiências públicas, debates e notícias. Também foram realizadas entrevistas com representantes de diversas categorias de atores, incluindo corporações profissionais, mídia, academia e sociedade civil organizada. Por meio da análise do processo de mobilização e dos argumentos centrais que apelaram para a legitimidade da reforma (legitimacy accounts), os resultados apontaram para: (a) a centralidade das corporações profissionais, tanto na mediação e tradução do debate, quanto no desenho de estratégias de intervenção no campo organizacional, e; (b) a identificação de aspectos organizacionais, relacionais, processuais, jurisdicionais e responsivos ligados à multidimensionalidade da legitimidade dos TCs. Os resultados contribuem para as áreas de estudos organizacionais, de administração pública e de administração da Justiça.

Palavras-chave: legitimacy accounts; corporações profissionais; reforma; tribunais de contas; administração da justiça.

\begin{abstract}
The objective of this research was to investigate the political-cultural process related to the debate on the reform of Brazilian Courts of Accounts (CAs), law enforcement organizations responsible for controlling public resources. The research focused on analyzing how legitimacy accounts conducted by different categories of actors manifested themselves in the debate about the reform of Brazilian CAs from 2000 to 2017. We collected data from documentary sources, such as parliamentary speeches, public hearings debates, and news. Interviews were also conducted with representatives of the various categories of actors, including professional corporations, media, academia, judiciary, and organized civil society. Through the analysis of the mobilization process and the central arguments that called for the legitimacy of reform (legitimacy accounts), the results pointed to: (a) the centrality of professional corporations, both in the mediation and translation of the debate, and in the design of intervention strategies in the organizational field, and; (b) the identification of organizational, relational, procedural, jurisdictional and responsive aspects related to the multidimensional legitimacy of CAs. The results contribute to the areas of organizational studies, public administration and administration of justice.
\end{abstract}

Keywords: legitimacy accounts; professional corporations; reform; courts of accounts; administration of justice.

JEL Code: D73, E6, H83. 


\section{Introdução}

A partir do contexto de organizações da Justiça, o objetivo desta pesquisa foi investigar, no período de 2000 a 2017, o processo político-cultural relacionado ao debate em torno da reforma dos Tribunais de Contas brasileiros (TCs), organizações responsáveis pela aplicação da lei e controle de recursos públicos. Para tanto, fez-se uso da noção de campo organizacional, enquanto recurso de delimitação da realidade analisada, e dos legitimacy accounts, como elementos discursivos com potencial para ilustrar o delineamento do debate e os aspectos multidimensionais e processuais de legitimidade emergentes dessa conjuntura.

Nesse sentido, em olhar retrospectivo, observa-se que, historicamente, o conceito de legitimidade tem sido alvo de estudos em diversas frentes da ciência, bem como associado, por exemplo, ao fundamento de uma ordem institucional, à atitudes de obediência frente a uma ordem social, a uma noção de validade social ou mesmo à percepção de desempenho organizacional (Diniz, 2005; Fix-Fierro, 2003; Johnson, Dowd, \& Ridgeway, 2006; Mariano, 2010). Quando relacionada ao contexto organizacional, a legitimidade assume a lógica de percepção da ação organizacional frente aos parâmetros de uma ordem social (Suchman, 1995), de modo que uma organização legítima estaria, portanto, suportada por princípios afetos ao sistema social em que está inserida (Berger, Ridgeway, Fisek, \& Norman, 1998; Rossoni, 2016).

Sob o olhar da legitimidade, um grupamento ainda pouco estudado no campo da administração, e que chama a atenção, é o das organizações da Justiça. Tal enfoque justifica-se pelos recorrentes questionamentos sobre a legitimidade dessas organizações nos últimos anos e pela relevância dessas entidades para o ordenamento social e estrutura institucional do Estado, já que são associadas à noção de influência sobre questões civilizatórias, de respeito às leis, de coesão social e de desenvolvimento social e econômico (Guimaraes, Gomes, \& Guarido Filho, 2018) ou mesmo entendidas como campo de influxo sobre os "litígios submetidos ao Poder Judiciário" (Akutsu \& Guimarães, 2015, p. 942).

Exemplos podem ser encontrados no campo das organizações do Judiciário, com questionamentos sobre a isenção e imparcialidade dos julgamentos e juízes, sobre as fronteiras da judicialização de temáticas específicas e sobre o ativismo judicial e a condução de medidas coercitivas (Guarido Filho, Luz, \& Silveira, 2018); no campo das organizações policiais e prisionais, no que se refere aos abusos de autoridade dos seus integrantes frente à política de interação social adotada por essas organizações (Laniado, 2000; Ribeiro \& Machado, 2014); e ainda no campo dos órgãos de controle de modo em geral, no tocante ao domínio seletivo de ações de fiscalização, julgamento de contas públicas e apuração de conformação legal (Consultor Jurídico [Conjur], 2017; Conti, 2016, 2017; J. M. Oliveira, 2017; Silva, 2017; Viana, 2017).

Sobre o último conjunto de organizações mencionado, especificamente no que se refere aos Tribunais de Contas (TCs) brasileiros, algo que desperta a atenção tem sido o debate em torno da reforma dessas organizações ao longo dos últimos anos (Azevedo \& Lino, 2018; Lino \& Aquino, 2018; Loureiro, Teixeira, \& Moraes, 2009). Tal espaço tem se constituído como campo de diálogo e discussão promovido por diferentes atores interessados, tais como corporações profissionais, mídia, sociedade civil organizada, judiciário e academia, assim como tem trazido à tona aspectos multidimensionais ligados à composição da legitimidade organizacional dos TCs, em especial no tocante à questões organizacionais, relacionais, processuais, jurisdicionais, sociais e de responsividade.

Dessa forma, frente a existência ampla e consolidada no cenário mundial das entidades de fiscalização superior (EFS), no contexto brasileiro, os 33 TCs existentes vêm se destacando pela atuação organizacional associada a questões de fomento à boa governança, de combate à corrupção e de fortalecimento da transparência nos três níveisde governo, evoluindo historicamente de uma estética de atuação relacionada à auditorias das contas públicas para um formato de intervenção mais ligado à accountability (Carvalho, 2008). Frente a isso, tais organizações exercem funções ligadas à aplicação da lei e ao controle de recursos públicos, por meio de ações de fiscalização sobre órgãos e entidades públicas, e de julgamentos de contas de gestores e demais responsáveis por recursos públicos. 
Esse cenário de relevância, no entanto, quando contextualizado em meio a alguns casos críticos ocorridos em nível nacional, abre espaço para discussão sobre a legitimidade e as reformas necessárias no contexto dessas organizações (Lino \& Aquino, 2018). Constatações podem ser observadas: (a) no desenho da crise fiscal dos Estados Federados frente a aprovação das contas dos respectivos gestores pelos TCs (J. M. Oliveira, 2017); (b) na emissão, por parte do Tribunal de Contas da União (TCU), de parecer prévio pela reprovação das contas do exercício de 2014 da Presidente da República em meio a um contexto de movimentação política intensa (Conti, 2017); (c) nos escândalos de corrupção envolvendo membros dos TCs apurados em operações de investigação interinstitucionais, tais como a Lava-Jato (Araújo, 2017; G1, 2017; O Globo, 2017) e; (d) na extinção recente de um tribunal de contas no estado do Ceará (G1 CE, 2017a, 2017b).

A noção de legitimidade organizacional associada ao contexto organizacional dos TCs traz, portanto, contribuições para a perspectiva dos estudos organizacionais, de administração pública e de administração da Justiça, ao buscar uma visão reflexiva sobre a legitimidade de um grupo específico de organizações inseridas no contexto da administração pública brasileira. Traz ainda, do ponto de vista empírico, reflexão sobre campo de grande relevância para o ordenamento público nacional , composto por organizações de controle que, embora institucionalizadas no contex to de Estado, têm sido elementos centrais de debates históricos, com direcionamentos em determinados momentos, inclusive, apontando para a sua extinção.

Assim, diante do contexto apresentado, o estudo ${ }^{1}$ teve como objetivo analisar como legitimacy accounts conduzidos por diferentes categorias de atores, legais e não legais, manifestaram-se no debate acerca da reforma dos TCs brasileiros no período de 2000 a 2017. Para tanto, abordou-se inicialmente o desenho teórico dos conceitos de legitimidade organizacional e legitimacy accounts. Em seguida, sob o ponto de vista metodológico, pontuou-se sobre os procedimentos realizados para o desenvolvimento do estudo. Então, sob o prisma da discussão e dos resultados, retratou-se: (a) o processo de mobilização sobre a reforma e os argumentos centrais usados por diferentes categorias de atores, e; (b), por meio dos elementos discursivos (legitimacy accounts) circunscritos aos argumentos centrais, foram identificados os aspectos emergentes relacionados à multidimensionalidade da legitimidade dos TCs. Por fim, encerrou-se o artigo com recomendações de que os aspectos abordados neste estudo sejam explorados em trabalhos futuros.

\section{Legitimidade Organizacional e Legitimacy Accounts}

O presente trabalho se fundamenta na noção processual de legitimidade organizacional, recorte em que se admite (a) o foco na representação organizacional das instituições e, (b) a noção contestada, construída e negociada da legitimidade por meio da interação entre os atores interessados. Nesse sentido, o quadro teórico do trabalho foi elaborado a partir discussão sobre legitimidade, legitimidade organizacional e organizações da Justiça, para então, em sequência, seguir com os recortes de imersão institucional, campo organizacional e, por fim, abordagem processual e componente discursivo (legitimacy accounts).

A legitimidade, embora amplamente utilizada no plano empírico e teórico, apresenta-se enquanto conceito polissêmico e insipiente do ponto de vista da precisão e delimitação conceitual (Suddaby, Bitektine, \& Haack, 2017). Pode-se observar, por exemplo, que quando concebida no âmbito das teorias jurídicas, a legitimidade enfoca a representação jurisdicional e dos tribunais constitucionais (Agra, 2005; Diniz, 2005; Mariano, 2010), sendo sustentada tanto pela lógica do formalismo legal (Diniz, 2005), quanto por um dinâmica responsiva (Friedman, 2016; Kagan, 2009). Por outro lado, a legitimidade poderia ser vinculada à inserção do agir organizacional no contexto social em que está inserido (Berger et al., 1998; Rossoni, 2016; Suchman, 1995).

Nessa toada, com base no foco organizacional da legitimidade e frente a ampla gama de organizações, algo chama a atenção para as organizações da Justiça e, de modo específico, para o 
contexto dos TCs. Tal atenção é justificada na medida em que, embora consideradas institucionalizadas no ordenamento social e influentes na vida em sociedade, as cortes de contas tem sido alvo de debate em torno do aperfeiçoamento de questões relacionais, de composição estrutural e de transparência organizacional ligadas à sua atuação. De modo prático, tais contornos discursivos têm, em grande medida, sinalizado para condicionantes processuais e recortes dimensionais relacionados à aspectos de legitimidade emergentes ao contexto dessas organizações.

Com vistas a melhor ilustrar isso, sob o ponto de vista empírico, diversos estudos, em nível internacional e nacional, têm envidado esforços no sentido de compreender o fenômeno da legitimidade, seus condicionantes e seu processo de emergência no contexto específico das organizações da Justiça. No âmbito internacional, pode-se citar estudos que abordam a legitimidade em face de variáveis como difusão, relevância e satisfação com resultados (Gibson, Caldeira, \& Baird, 1998), ideologia e satisfação relacionados ao desempenho (Gibson \& Nelson, 2015), símbolos judiciais (Gibson, Lodge, \& Woodson, 2014), percepção e julgamento (Gibson \& Caldeira, 2009), política judicial (Clark, 2009), aparências (Bybee \& Narasimhan, 2015) e ideia manipulável (Power, 2000). Já no plano nacional, pode-se citar os estudos voltados para a relação entre legalidade, legitimidade e organizações, a exemplo dos voltados para a temática de processos licitatórios enquanto mito racional na administração pública (Guarido, Guarido Filho, \& Eberle, 2017), de construção social do sistema de identificação brasileiro (Akiyama, Almeida, Godri, \& Guarido Filho, 2015) e da reputação do Judiciário (Bolonha, Vasconcelos, \& Mattos, 2017).

Ao variar o foco de exame, pode-se avançar para a compreensão do conceito para o âmbito organizacional, cuja interpretação assume a lógica de "percepção ou pressuposição generalizada de que as ações de uma entidade são desejáveis ou apropriadas dentro de algum sistema socialmente construído de normas, valores, crenças e definições" (Suchman, 1995, p. 574), reforçando que as organizações se tornam legítimas quando suportadas por princípios afetos ao sistema social em que estão inseridas (Berger et al., 1998; Rossoni, 2016). Desse modo, a legitimidade organizacional estaria inserida no componente teórico integrante do institucionalismo organizacional, que parte da compreensão de que as organizações precisam não somente de recursos utilitaristas, mas também aceitação e credibilidade para se tornarem perenes em seu ambiente social (DiMaggio \& Powell, 1991; Greenwood, Oliver, Sahlin, \& Suddaby, 2008; Scott, 2008).

Conforme entendimento construído, um recorte útil é o de campo organizacional, identificado como perspectiva meso de análise que destina atenção para o processo de orientação das ações de campo por um determinado conjunto de atores (Kluttz \& Fligstein, 2016). Tal configuração específica admite a noção de imersão institucional e, por conseguinte, a compreensão dos níveis individual ou organizacional a partir de contextos societais (Friedland \& Alford, 1991). Ao considerar a vastidão de apreensões teóricas sobre campos organizacionais, Machado-da-Silva, Guarido Filho e Rossoni (2006) sistematizaram seis perspectivas teóricas sobre o conceito, que variam desde uma noção de significação ou mesmo poder e conflito, até um recorte discursivo, atinente à tônica de debate, e relacional.

Ademais, considerando que, em parte, o debate sobre legitimidade e sobre a reforma dos TCs ocorre no campo discursivo, tal espaço remete à possibilidade de recuperação de uma noção processual de análise, que expande a noção dicotômica, de legítimo versus ilegítimo, para uma noção de construção da legitimidade, podendo ser compreendida como "um conjunto estruturado ou conjuntos de atividades formais ou emergentes que descrevem como um ator adquire associação com uma ordem ou categoria social existente" (Suddaby et al., 2017, p. 462). Assim sendo, uma vez fundamentada na noção processual, a legitimidade transitaria por um entendimento de algo construído socialmente e, sobretudo, negociado a partir das intermediações efetuadas pelos atores que compõem o campo organizacional, diferindo-se, portanto, das noções de propriedade e percepção, em que são apontadas alegorias de legitimidade enquanto recurso e julgamento social.

Ainda de acordo com a perspectiva processual, três possibilidades de compreensão dos processos de legitimação são possíveis: a primeira foca no uso da linguagem e comunicação como mecanismos de construção de significado; a segunda está relacionada à teorização, representada pelo processo de abstração de práticas existentes em categorias generalizadas; já a terceira possibilidade remete à ideia 
de identificação/categorização, referenciando a legitimação com base em esforços de manutenção, ao mesmo tempo, de uma lógica isomórfica e diferenciada por parte das organizações mediante o contexto em que estão inseridas (Suddaby et al., 2017). A noção de capital linguístico proposta por Bourdieu também sinaliza para a importância da dimensão discursiva na representação social da realidade ao reforçar que "as palavras não são simplesmente descritivas da realidade, mas constroem a realidade ... ter a última palavra é ter o poder sobre a representação legítima da realidade" (Bourdieu, 2014, p. 431).

Associada à menção de processualidade da legitimidade, que situa as "organizações em espaços de ordenação local onde estão sujeitas a contínua e dispersa avaliação de aspectos influenciadores de sua legitimidade" (Guarido Filho et al., 2018, p. 1), um recurso potencial para a identificação de possíveis fontes de legitimidade estaria nos legitimacy accounts, considerados dentre explicações, desculpas e justificativas que, sob o manuseio das organizações, são utilizadas para invocar (Ashforth \& Gibbs, 1990), ou mesmo para desenhar estratégias de manutenção da legitimidade organizacional, com base em contornos discursivos de proteção, afirmação e apelação (Sheridan \& Mote, 2017).

No plano empírico alguns estudos podem ser mencionados como forma de ilustrar a aplicação dos legitimacy accounts em contextos de análise que, em primeira vista, pode ser entendida como recurso metodológico para identificação de accounts no contexto de análise e, em segundo momento, como elemento próprio dos atores para tratar da legitimidade em nível de campo.

No primeiro caso, menciona-se, por exemplo, o estudo desenvolvido por Sheridan e Mote (2017) em que os autores, por meio do debate relacionado com a certificação de alimentos orgânicos do Departamento de Agricultura dos EUA, analisaram como as organizações apelam para a legitimidade em campos instáveis. Destaca-se ainda o estudo de Elsbach (1994), em que investigou a relação entre os accounts capturados de porta-vozes da indústria de gado da Califórnia e o gerenciamento de percepções de legitimidade organizacional. Por fim, Lamertz e Baum (1998), acompanharam o processo de legitimação cognitiva do downsizing organizacional ao longo do tempo por meio dos accounts emergentes dos relatórios de jornais de demissões. Já no segundo caso, menciona-se o estudo de Creed, Maureen e Austin (2002), que relacionaram os legitimacy accounts em favor e contra as políticas que impedem a discriminação no local de trabalho contra pessoas homossexuais, lésbicas, bisexuais e transgêneros, de modo a buscar compreender seu uso em ambientes locais por meio de accounts culturais mais amplos.

Dessa forma os legitimacy accounts têm sido usados como recurso útil para viabilizar a emersão de fatores de legitimidade relacionados a diversas temáticas, apontando para um papel organizacional dentro desse contexto. A seção seguinte tratou dos aspectos metodológicos atinentes ao contexto do estudo realizado.

\section{Procedimentos Metodológicos}

Com o fito de alcançar o objetivo de pesquisa, o estudo foi delineado sob um caráter exploratóriodescritivo, com cunho qualitativo, horizonte temporal longitudinal (Saunders, Lewis, \& Thornill, 2009) e estratégia de pesquisa de estudo de caso (Yin, 2001), em linha ao que discutiram Machado-da-Silva, Fonseca e Crubelatte (2005) sobre a complexidade dos fenômenos e das relações presentes em contextos de abordagens sistêmicas processuais recorrentes, como sugere ser a presente situação em estudo.

Seu marco de delimitação temporal foi definido no período de 2000 a 2017. Dessa forma, remontou ao ano de 2000, em função da intensa movimentação legislativa sobre a temática, transitou até o ano de 2010, período em que se percebeu diversos esforços político-institucionais no sentido de positivar determinadas discussões no plano legal e se estendeu até o ano de 2017 , momento em que o fenômeno ainda se encontra em curso.

O nível de análise adotado foi o de campo organizacional, considerado apropriado por não apenas favorecer a atenção à dimensão relacional entre organizações, como também por considerar aspectos 
ideacionais construídos e tomados como referência para a ação (Machado-da-Silva, Guarido Filho, \& Rossoni, 2006). Dessa forma, distanciando-se da compreensão de causalidade (Creswell, 2007), a pesquisa considerou atores legais e não legais identificados como partícipes do processo em análise e apontou como unidade de análise o próprio debate em torno da reforma dos TCs e suas movimentações estratégicas e discursivas decorrentes.

A etapa de coleta de dados da pesquisa consistiu no levantamento de dados primários e secundários e foi dividida em duas etapas: (a) realização de pesquisa documental e; (b) aplicação de entrevistas, ambas coletadas entre agosto de 2017 e janeiro de 2018.

Em relação à primeira etapa, atinente à coleta exploratória de dados secundários, foram considerados, frente ao intuito de cobrir o debate no tocante à aspectos de legalidade, 50 documentos do poder Legislativo dentre projetos de emenda à constituição (PECs) e suas respectivas exposições de motivos (entre 1995 e 2017), vídeos de audiências públicas e discursos parlamentares. No tocante à cobertura de aspectos de comportamento organizacional frente ao campo, também foram consultados 23 portais e 31 cartas de intenção das corporações profissionais ligadas aos TCs. Nessa linha, páginas virtuais em redes sociais, debates e exposições sobre a reforma dos TCs também foram utilizadas. Ademais, sob a ótica da repercussão social, foram consideradas 71 publicações da mídia que não apresentavam caráter acadêmico e científico, mas que, no decorrer da análise, fizeram-se importantes para a compreensão do contexto analítico.

A segunda etapa da coleta de dados consistiu na realização de vinte e uma entrevistas semiestruturadas envolvendo representantes de diferentes categorias de atores, legais e não legais, do campo organizacional em análise, a saber: corporações profissionais, academia, judiciário, mídia e sociedade civil organizada. Tais entrevistas totalizaram $15 \mathrm{~h}$ e $22 \mathrm{~min}$ e apresentaram uma duração média de $43 \mathrm{~min}$, sendo distribuídas em corporações profissionais (onze entrevistas $/ 9 \mathrm{~h} 48 \mathrm{~min}$ ), academia (uma entrevista/30 min), judiciário (uma entrevista/18 min), mídia (três entrevistas/1h 09min) e sociedade civil organizada (cinco entrevistas/3h $37 \mathrm{~min}$ ).

O critério de escolha da composição inicial de entrevistados, pertencentes à categoria de corporações profissionais, deu-se em função do protagonismo e inserção no debate por parte dos indivíduos escolhidos e das organizações que representam, de modo a servir para uma compressão mais apurada e para um melhor desenho da capilaridade do debate. As demais escolhas foram efetuadas com base na técnica de bola de neve (Creswell, 2007) e se assentaram na ideia de ampliação da cobertura de atores em nível de campo, de forma a possibilitar a triangulação de informações a partir de diferentes perspectivas e a captura de focos residuais do debate.

Com o auxílio do software NVivo®, a técnica de análise de conteúdo (Bardin, 2011) foi utilizada para o exame dos dados. Nesse sentido, quanto ao protocolo de pesquisa, o trabalho contou com duas etapas: (a) a primeira, de natureza descritiva, consistiu na contextualização histórica dos TCs no período demarcado, no caso 2000 a 2017, sinalizando para as bases em que se deu o debate em torno da reforma dessas instituições, de modo que, sem critérios previamente definidos, foram levantados incidentes críticos relacionados ao debate, e; (b) a segunda etapa, de natureza exploratório-descritiva, consistiu no levantamento dos argumentos centrais do debate e, consequentemente, dos legitimacy accounts (elementos discursivos) sob a ótica de categorias de atores, legais e não-legais, de modo que, fundamentados nos dados primários e secundários levantados, foram extraídos trechos que remetessem aos elementos centrais do debate e aos accounts (explicações, desculpas e/ou justificativas utilizadas pelos atores para invocar a legitimidade organizacional), posteriormente codificados e agrupados em núcleos de sentido relacionados ao debate sobre a reforma dos TCs.

Assim sendo, sob um olhar operacional, as questões temáticas centrais ao debate em torno da reforma emergiram da análise exploratória e da codificação de nós, agrupamentos de informações, efetuadas a partir dos dados primários e secundários coletados. Com o intuito de lançar luz sobre o posicionamento discursivo dos atores, legais e não legais, partícipes do debate, o material coletado também foi codificado por categoria de ator, a saber: corporações profissionais, academia, judiciário, mídia, sociedade civil organizada e Legislativo. Tais frentes de codificação em categorias emergentes, 
possibilitaram a identificação de legitimacy accounts ligados à determinados aspectos da legitimidade organizacional associados ao debate em torno da reforma dos TCs e aos próprios tribunais.

\section{Resultados e Discussão}

Esta seção foi dividida em duas partes: (a) a primeira consistiu no descritivo de incidentes críticos que influenciaram na formação do debate sobre a Reforma dos TCs no período de 2000 a 2017, e; (b) a segunda apresentou os argumentos centrais do debate e os legitimacy accounts sob a ótica dos grupamentos de atores elencados neste estudo.

\section{Tribunais de Contas: contexto e bases da reforma no Brasil}

Após a promulgação da Constituição Federal da 1988, no período de 2000 e 2017, alguns acontecimentos relacionados aos TCs continuaram a implicar na vida organizacional dessas organizações, tais como incidentes de natureza cultural, política, econômica, legal, normativa ou mesmo responsiva. Assim sendo, a análise dos incidentes a seguir foi ordenada em dois períodos: 2000 a 2010, em um primeiro momento, e 2011 a 2017, em um segundo momento.

O primeiro período de análise (2000 a 2010) foi marcado, sob um panorama político e por volta dos anos 2000, por uma crise de legitimidade dessas organizações, fomentada por instituições multilaterais e auditorias privadas, bem como por parte de setores do parlamento e mídia (Lins, 2000). Sob essa ótica observou-se repercussão em nível legal que, mediada por propostas de emenda à constituição (PECs), revelou recorrentes menções à extinção dessas organizações em função de aspectos ligados à economia de recursos públicos, à eliminação de duplicidade de atuação, ou mesmo à efetividade no controle externo exercido sob uma ótica privada.

A par do cenário relatado, outros incidentes críticos influenciaram as atividades dos TCs, como as edições da Lei de Responsabilidade Fiscal (LRF), em 2000, e da Lei da Ficha Limpa, em 2010, principalmente pelo impacto gerado com o reforço da noção social de TCs atrelados ao planejamento e controle das contas públicas, com repercussão da atuação de controle na inelegibilidade de candidatos a cargos políticos, conforme se pode observar pelo relato do entrevistado 3 da categoria de corporações profissionais ao afirmar que "a Lei da Ficha Limpa criou uma atenção para os TCs, assim como a LRF". Menciona-se ainda a Reforma do Judiciário, com a criação do Conselho Nacional de Justiça (CNJ), para o contexto do Poder Judiciário, e do Conselho Nacional do Ministério Público (CNMP), para o contexto do Ministério Público, como fator desencadeador de debates concernentes à necessidade de criação de uma instância de controle externo para esse conjunto de organizações, conforme relatos encontrados em grande medida nas categorias de corporações profissionais e sociedade civil organizada.

Ademais, como contrapartida dos TCs à instabilidade do campo, menciona-se o Programa de Modernização do Controle Externo dos Estados e Municípios Brasileiros (PROMOEX) que, desenhado mediante parceria entre os TCs e o Governo Federal com financiamento do Banco Interamericano de Desenvolvimento (BID), objetivou a modernização e a integração dos órgãos de controle externo nacionais em cinco frentes temáticas: (a) integração externa, (b) planejamento e controle de gestão, (c) métodos e processos de trabalho, (d) tecnologia da informação e, (e) estrutura e gestão dos recursos humanos. Tal iniciativa impulsionou dinâmicas de integração, internacionalização e ressignificação de atores associados aos TCs, conforme se pode depreender da fala do Entrevistado 11.

"o PROMOEX, eu considero uma primeira grande revolução dos tribunais no pós CF/88. Com isso, a própria ATRICON começou a ter uma visão de querer deixar de ser apenas uma associação de classe" (Entrevistado 11 - Corporações Profissionais).

Já no segundo período de análise (2011 a 2017), alguns fatores chamaram atenção como a deflagração da Operação Lava-Jato enquanto mecanismo contextual que, no contexto de combate à 
corrupção, influenciou a ressignificação do espaço público quanto à valorização da transparência, do controle social e do comportamento ético na política, quer seja na atuação das organizações públicas ou mesmo na relação entre o público e o privado. A crise fiscal dos Estados também salientou responsabilidades atribuídas aos TCs, desnudando fragilidades e oportunidades de melhoria. Conforme relato dos entrevistados:

“esses escândalos de corrupção que a Lava-Jato e seus desdobramentos estão mostrando que a corrupção também estava entranhada em vários TCs" (Entrevistado 02 - Corporações profissionais).

"fatos recentes colocaram os TCs na berlinda, a começar pelos gravíssimos problemas que estão sendo enfrentados pelos diversos estados brasileiros ... a pergunta que a sociedade faz é a seguinte: aonde estavam os TCs quando todo esses fatos aconteceram ou vieram acontecendo?" (Entrevistado 17 - Sociedade Civil Organizada).

Ainda sobre o contexto de reconstrução do espaço público e do papel dos TCs, mencionam-se as manifestações ocorridas em 2013 e o julgamento das contas da presidência da República em 2015, com a recomendação de reprovação das contas examinadas pelo TCU, como fatos que lançaram luz sobre a atuação e o significado dos TCs. Nesse sentido, foi possível reconhecer que pesquisas em nível nacional e o advento das redes sociais também instrumentalizaram o debate em torno dos TCs. É possível citar, por exemplo, a recente pesquisa realizada pelo IBOPE, em que se observou que $68 \%$ dos 2002 entrevistados em território nacional desconheciam a natureza dos TCs (IBOPE, 2016), ou mesmo o levantamento realizado pela ONG Transparência Brasil sobre a vida pregressa dos 233 conselheiros em exercício nas 34 cortes de contas, marco que destacou questões políticas, éticas e morais incompatíveis com o cargo (Sakai \& Paiva, 2016).

Sob o ponto de vista da interlocução com Poder Judiciário, algumas posições também suscitaram investidas sobre as competências e a legitimidade dos TCs, a saber: a decisão do STF sobre a competência exclusiva da Câmara Municipal para julgar as contas de governo e as contas de gestão dos prefeitos, cabendo às cortes de contas auxiliar o Poder Legislativo municipal em 2016, ou mesmo a discussão relativa ao poder de cautelar dos TCs (Abraham, 2016), representado por medidas tomadas em situações de urgência e de iminente lesividade ao erário ou direito alheio, e questionado sob a ótica de repercussão e responsabilidade dessas organizações "quando se consideram medidas que podem suspender julgamentos com ampla repercussão do ponto de vista político e administrativo" (Entrevistado 13 - Judiciário).

Outrossim, quanto ao nível associado ao comportamento interinstitucional, alguns pontos foram verificados como: uma atuação mais efetiva das corporações profissionais no tocante às discussões estruturais afetas à temática, movimentação que se deu por intermédio de programas destinados a discutir e direcionar ações no campo organizacional, como o Programa Qualidade e Agilidade nos Tribunais de Contas (QATC), que incluiu a elaboração de diretrizes institucionais e a aplicação de um Marco de Medição de Desempenho (MMD), como marcos de desenvolvimento (Associação dos Membros dos Tribunais de Contas do Brasil [Atricon], 2017a). Nesse nível, cita-se ainda uma maior incidência de escândalos de corrupção relacionados a atores ligados aos TCs e identificados, a título exemplificativo, nas operações da política federal Mãos Limpas e Quinto do Ouro (Araújo, 2017; G1, 2017; O Globo, 2017), bem como a extinção do Tribunal de Contas dos Municípios do Estado do Ceará (TCM/CE) (G1 CE, 2017a, 2017b).

Por fim, observou-se ainda uma movimentação de setores da sociedade no sentido de construir uma lógica responsiva e social sobre o debate em torno da reforma, de modo a infundi-la com valores oriundos do contexto de mobilização social. Essa lógica foi evidenciada com base nas campanhas de conselheiro cidadão, no movimento de juristas, no movimento de conselhos profissionais das áreas de administração, ciências contábeis, direito e economia e nos movimentos mais amplos como o MUDA $\mathrm{TC}$, que apresentaram uma base discursiva associada, em primeiro momento, em movimentações pautadas no caráter estritamente institucional, técnico e isento de questões e interesses de segmentos particulares e, em segundo momento, associada a um sentimento geral de aperfeiçoamento do sistema, considerando a infusão de valores técnicos e sociais, bem como a efetiva participação da sociedade civil organizada. 


\begin{abstract}
“considerando que os interesses não são meramente classistas, são interesses institucionais, ou seja, todos se unem em busca do aperfeiçoamento. É a partir daí que surge o MUDA TC, é a partir daí que surgem as campanhas de conselheiro cidadão, que diverge da campanha conselheiro técnico. A campanha conselheiro técnico, eu diria que está centrada em arregimentar um técnico do controle externo para poder conduzir esse processo de eleição, diferente da campanha conselheiro cidadão, em que eu posso arregimentar alguém da sociedade, técnico ou não. Mas de qualquer modo a união dessas entidades classistas, seja em defesa de uma campanha de conselheiro cidadão ou técnico, dá-se com esse objetivo de aperfeiçoar o sistema, de garantir que o sistema como um todo, ou seja, sem atalhos, permaneça hígido" (Entrevistado 07 Corporações profissionais).
\end{abstract}

A partir do cenário supramencionado, foi possível, no período de 2000 a 2017, recuperar a reforma dos TCs como espaço de discussão e diálogo em que vários atores têm questionado e ao mesmo tempo construído a legitimidade dessas organizações. Desse modo, é frente ao debate narrado que os legitimacy accounts serão utilizados como forma de expressão dos atores no âmbito discursivo, mas também como um recurso de viabilização da análise empírica que virá a seguir. Frente a isso, a próxima seção abordará os aspectos centrais da discussão em torno da reforma dos TCs sob a ótica de atores legais e não legais e levantará os accounts e aspectos de legitimidade emergentes do debate associado a esse contexto.

\title{
Legitimacy accounts sob a ótica de atores legais e não legais
}

Nos cenários, nacional e internacional, as entidades de fiscalização superior (EFS) têm, historicamente em plano empírico, sido alvo de debates, sob as mais diversas perspectivas e olhares, relacionados a questões de estrutura, composição, atividades exercidas e impactos de atuação. Willeman (2017), ao mencionar aspectos relacionados ao interesse de pesquisadores que estudam o desenho institucional dos TCs, aponta para questões como:

(i) a extensão do controle a cargo das ISCs; (ii) o momento em que o controle é exercido; (iii) a capacidade de enforcement das ISCs; (iv) a sujeição das ISCs à accountability diagonal e, finalmente, (v) os riscos e as patologias da denominada accountability overload, ou seja, dos excessos de instituições e de mecanismos de controle e supervisão (Willeman, 2017, p. 67).

Seguindo o esforço realizado por Willeman (2017), no tocante ao levantamento de pontos de debate e interesse em torno dos TCs e da atividade de controle, e com o intuito de dialogar nessa perspectiva, foi que a análise, demarcada pelo campo e marco temporal deste estudo, no caso o período de 2000 a 2017, encaminhou-se para a identificação de aspectos discursivos (legitimacy accounts) relacionados ao debate em torno (a) da ausência de controle externo sobre as atividades dos TCs, (b) da assimetria processual e de estrutura organizacional entre os TCs, (c) da influência de atividade política sobre os TCs, (d) da interferência entre as três funções que perpassam o processo de controle externo, a saber: de auditoria, ministerial e de julgamento e, (e) da ausência de transparência institucional e das atividades de controle externo. Cada um deles será tratado na sequência.

Ausência de controle externo sobre as atividades dos TCs. O primeiro aspecto mencionado, relacionado à necessidade do exercício de controle organizacional externo e independente sobre as atividades dos TCs e dos julgadores que os integram, surgiu em função de aspectos ligados ao envolvimento de membros dos TCs em investigações de corrupção, como a Operação Quinto do Ouro, realizada no Rio de Janeiro, contexto reforçado pela associação do TC com estruturas de controle de outras organizações, como o Conselho Nacional de Justiça (CNJ), para o poder Judiciário e o Conselho Nacional do Ministério Público (CNMP), para o Ministério Público.

Nesse sentido, dentre as medidas propositivas emergidas do debate, foi possível identificar um direcionamento para a necessidade de criação de uma instância de controle para os TCs, quer seja pela criação de um Conselho Nacional dos TCs (CNTC) ou mesmo mediante a submissão dos membros dos TCs ao CNJ e dos membros do Ministério Público de Contas ao CNMP. Sobre o CNTC, os argumentos favoráveis giraram em torno da impossibilidade de submissão dos TCs ao CNJ por questões de juridicidade e inconstitucionalidade, especificamente em função do princípio jurídico da separação de 
poderes e em função do know how que um conselho específico poderia ter em relação a aspectos como desempenho e questões processuais. Já no que se refere à submissão dos membros dos TCs ao CNJ e dos membros do Ministério Público de Contas ao CNMP, os argumentos de defesa destacaram a similaridade do contexto do Judiciário face a realidade dos TCs e a limitação orçamentária e fiscal para a criação de uma nova unidade como pontos favoráveis.

\begin{abstract}
“A gente em princípio é contra o $\mathrm{CNJ}$, porque tem a questão da juridicidade e da inconstitucionalidade disso, e de se pensar que um conselho também tem o objetivo de cuidar do desempenho e da parte processual. O Judiciário não tem esse know how em nossa área" (Entrevistado 12 - Corporações profissionais).
\end{abstract}

não há nenhuma intromissão de um poder em outro se a fiscalização dos TCs for exercida pelo $\mathrm{CNJ}$, pelo contrário, é o órgão que tem mais proximidade e familiaridade com a estrutura e modo de funcionamento dos TCs, organizado na forma de um tribunal, com processo, com o devido processo legal e com membros que tem todas as garantias da magistratura (Presidente de corporação profissional - Associação Nacional dos Auditores de Controle Externo dos Tribunais de Contas do Brasil [ANTC], 2017).

Assimetria processual e de estrutura organizacional entre os TCs. Sobre o segundo aspecto, o debate caminhou para a proposta de padronização do processo de controle externo e das estruturas organizacionais em nível nacional, a fim de se constituir uma normalidade de funcionamento. Como medidas propositivas, extraiu-se aspectos de padronização do processo de controle e da estrutura organizacional dos TCs, representados pela aprovação de um código nacional de processo de controle externo (O. C. Oliveira, 2008) e de uma lei orgânica nacional para os TCs. Do primeiro caso, partiriam parâmetros de organização e funcionamento dos órgãos de julgamento e de auditoria dos TCs, bem como normas disciplinares para Ministros, Conselheiros e seus substitutos, Procuradores e Auditores de Controle Externo. Do segundo caso, partiriam normas processuais para a esfera de controle externo.

uma alteração muito importante que é a criação de uma lei complementar para estabelecer a organização, fiscalização, competência dos processos nos TCs, isto é muito importante para a $\mathrm{OAB}$, em especial porque eu que milito há mais de 20 anos em TCs Brasil afora e tenho a dizer aos senhores que a experiência como advogado tem sido difícil, pelo menos nos primeiros 10 anos, até eu descobrir como funcionavam os processos dentro dos TCs (Representante da OAB ANTC, 2017).

entre as matérias de competência legislativa privativa da União, estaria a edição de "Código de Processo Civil" de Contas, de iniciativa do TCU. Esse diploma fixa tipologias e questões ainda não pacificadas como conceitos de Contas de Gestão e Contas de Governo. O objetivo da padronização é reduzir algumas das assimetrias que ainda existem no sistema e garantir mais segurança a todo processo de contas (Atricon, 2017b, p. 8).

Influência de atividade política sobre os TCs. Sobre o terceiro aspecto do debate e com referência aos componentes políticos de seleção/ingresso e composição ao qual os TCs estão submetidos, foi possível depreender que, embora as estruturas legais estipulem, segundo os parágrafos $1^{\circ}$ e $2^{\circ}$, do artigo 73 da CF/88 os critérios para nomeação dos ministros e, por simetria, os conselheiros dos TCs, bem como as formas de escolha dos membros, de forma segmentada entre o Poder Executivo e o Poder Legislativo, esses elementos foram relativizados ou foram objeto de questionamento, conforme falas transcritas abaixo.

"você tem veterinário, jornalista, enfim, gente sem nenhuma expertise julgando conta pública ... encontra ministro julgando empreiteira da Lava Jato que, ao mesmo tempo, está sendo investigado na Lava Jato" (Entrevistado 15 - Mídia).

não faz sentido um governador do Estado poder livremente escolher quem vai fiscalizar suas contas. Isso não tem como dar certo, isso não pode funcionar, é um problema de desenho institucional. (Deputado Federal, MUDA TCE-RJ, 2017) 
Como medidas propositivas em relação a esses pontos, emergiram questões como a objetivação dos critérios de escolha dos membros das instâncias deliberativas dos TCs e a majoração da participação técnica na composição dessas instituições. Sob a primeira frente, o direcionamento do debate privilegiou proposições de ajuste da composição para a formação de uma maioria técnica e de qualificadores das indicações políticas que ainda permanecerem. Desse modo, para o contexto das indicações, aplicar-se-ia o fim das indicações livres do Poder Executivo e a preservação das indicações do Legislativo, por outro lado, dentro do contexto dos candidatos aos cargos, firmar-se-iam critérios de escolha tais como: quarentena de três anos desde o término de mandato eletivo, inexistência de condenações judiciais e contas reprovadas, graduação e experiência em áreas intimamente ligadas à atuação dos TCs, sendo que as indicações precisariam de maioria absoluta para aprovação (Atricon, 2017b). Por outro lado, sob uma outra ótica, simplesmente o término das indicações políticas no âmbito dos TCs (Federação Nacional das Entidades dos Servidores dos Tribunais de Contas do Brasil [FENASTC], 2017). A segunda frente, relacionada à majoração do número de componentes integrantes das carreiras técnicas na composição dos TCs, tratou da pluralidade do órgão como forma de contrapor as facetas técnicas e políticas do contexto.

Interferência entre as três funções que perpassam o processo de controle externo, a saber: de auditoria, ministerial e de julgamento. Em relação ao quarto aspecto, as questões pontuadas giram em torno da ressignificação do papel da auditoria de controle externo (Viana, 2017), entendida como a função responsável pela elaboração do relatório que compõe a peça principal do processo de controle externo e pelo reexame dos achados de auditoria; da independência da atividade ministerial, representada pela análise do relatório e das razões da defesa; e da função judicante, responsável pela emissão de parecer e julgamento de contas (FENASTC, 2017). Em relação ao papel da auditoria de controle externo, observou-se que o processo de ressignificação perpassa por questões (a) de independência frente à função judicante, (b) de profissionalização e padronização a partir do contexto nacional e internacional e, (c) de constituição da identidade dos profissionais ligados a essa função, conforme relato do Presidente de corporação profissional.

a auditoria não é o cartório da vara do juiz, não é uma unidade administrativa, é um órgão que funciona com servidores de carreira e que precisa funcionar sob um padrão nacional. Hoje nós temos uma assimetria que está na raiz de muitas crises que temos em vários estados, e que está relacionada à falta de independência profissional desses atores. (Presidente de corporação profissional - ANTC, 2017).

No que se refere ao papel da função ministerial, verificou-se os seguintes núcleos de discussão: (a) a importância do MPC no contexto dos TCs; (b) independência dos Ministérios Públicos de Contas (MPC) em relação aos TCs e (c) a relação e integração dos MPCs com os outros ramos dos Ministério Público, fatos representados no trecho abaixo. Já sobre o papel da função judicante, sobressaltou a tônica de discussão adstrita aos aspectos de sobrevalorização dos critérios políticos frentes aos técnicos.

o parlamento não tem um ministério público especial. Os TCs possuem esse Ministério Público Especial porque o tribunal julga, porque a decisão dele tem eficácia de título executivo, ela não precisa ser discutida no Judiciário para cobrança. Então a Constituição previu um Ministério Público especializado em contas, em finanças, para dar concretude ao devido processo legal, daquele que tem as contas julgadas (Presidente de corporação profissional - ANTC, 2017).

Ausência de transparência institucional e das atividades de controle externo. $O$ quinto aspecto observado foi fundamentado no baixo grau de visibilidade das ações institucionais, do trâmite processual e do teor dos processos, denotando ações na seara da accountability organizacional, tanto do ponto de vista das atividades meio, quanto das atividades finalísticas prestadas pelos TCs, conforme relato do Presidente de corporação profissional.

Um ponto fundamental é a transparência dos TCs, que são órgãos hoje de uma opacidade tremenda. Um parlamentar federal que queira ter acesso a um relatório de auditoria que ainda não foi julgado pelo tribunal recebe um não ... o relatório de auditoria feito hoje não está disponível na internet para o parlamentar, nem para o MPF tomar ações de improbidade ou de persecução penal, se for o caso, nem para a sociedade exercer o controle social (Presidente de corporação profissional - ANTC, 2017). 


\section{Legitimacy accounts e a legitimidade processual e multidimensional dos TCs}

Ademais, de posse dos elementos centrais ao debate enquanto espaço de análise (Machado-daSilva et al., 2006), foi possível identificar elementos que remeteram aos aspectos de legitimidade associados aos TCs. A Tabela 1 revela que os legitimacy accounts identificados a partir dos atores pesquisados podem se constituir, em primeira análise, como representações de fatores de legitimidade associados à dimensões como: (a) controle externo sobre a atividade organizacional e decisor, (b) atividade processual, (c) organizacional, (d) jurisdicional (das decisões), (e) relacional e (f) responsiva e social.

Tabela 1

\section{Aspectos Centrais, Legitimacy Accounts e Aspectos de Legitimidade Emergentes}

\begin{tabular}{lll}
\hline Aspecto Central & Legitimacy accounts & Aspecto de legitimidade emergente \\
\hline $\begin{array}{l}\text { Ausência de controle } \\
\text { externo sobre as }\end{array}$ & $\begin{array}{l}\text { Criação de uma instância de controle } \\
\text { externo para os TCs, por meio da criação do }\end{array}$ & $\begin{array}{l}\text { Associado à dimensão de controle } \\
\text { atividades dos TCs o órgão e sobre o decisor }\end{array}$ \\
& CNTC ou por intermédio da submissão dos & \\
& membros dos TCs ao CNJ e do MPC ao & \\
& CNMP; & \\
\hline
\end{tabular}

\begin{tabular}{|c|c|c|}
\hline $\begin{array}{l}\text { Assimetria quanto à } \\
\text { realização do processo de } \\
\text { controle externo e à } \\
\text { efetivação da estrutura } \\
\text { organizacional dos TCs }\end{array}$ & $\begin{array}{l}\text { Padronização do processo de controle } \\
\text { externo e da estrutura organizacional dos } \\
\text { TCs, por meio da aprovação de um Código } \\
\text { Nacional de Processo de Controle Externo e } \\
\text { da aprovação de uma Lei Orgânica Nacional; }\end{array}$ & $\begin{array}{l}\text { Associado às dimensões processual e } \\
\text { organizacional; }\end{array}$ \\
\hline $\begin{array}{l}\text { Influência política sobre } \\
\text { os TCs }\end{array}$ & $\begin{array}{l}\text { Objetivação dos critérios de escolha dos } \\
\text { membros e majoração da participação } \\
\text { técnica nos TCs, por meio da } \\
\text { regulamentação dos critérios de escolha de } \\
\text { membros e da alteração de composição das } \\
\text { instâncias deliberativas das cortes de contas; }\end{array}$ & $\begin{array}{l}\text { Associado às dimensões relacional e } \\
\text { organizacional }\end{array}$ \\
\hline $\begin{array}{l}\text { Interferência entre as três } \\
\text { funções que integram o } \\
\text { processo de controle } \\
\text { externo: de auditoria, } \\
\text { ministerial e de julgamento }\end{array}$ & $\begin{array}{l}\text { Segregação das funções de auditoria, } \\
\text { ministerial e judicante, por meio da } \\
\text { regulamentação das três funções, } \\
\text { padronização do órgão de auditoria e } \\
\text { manutenção da independência do MPC; }\end{array}$ & $\begin{array}{l}\text { Associado às dimensões } \\
\text { organizacional, processual e } \\
\text { jurisdicional (das decisões); }\end{array}$ \\
\hline $\begin{array}{l}\text { Ausência de transparência } \\
\text { institucional e das } \\
\text { atividades de controle } \\
\text { externo }\end{array}$ & $\begin{array}{l}\text { Criação de mecanismos de transparência } \\
\text { institucional e processual para os TCs, por } \\
\text { meio de um portal de transparência nacional } \\
\text { e da divulgação ativa dos relatórios de } \\
\text { auditoria de cada TC; }\end{array}$ & $\begin{array}{l}\text { Associado às dimensões responsiva e } \\
\text { social. }\end{array}$ \\
\hline
\end{tabular}

Nota. Fonte: Elaborada pelos autores.

Ainda de acordo com a Tabela 1, os legitimacy accounts associados aos elementos centrais do debate sobre a reforma dos TCs, invocaram diferentes aspectos de legitimidade associados a essas organizações, constatação que se revela contraposta à noção de continuum entre ser legítimo e não legítimo, e endossadora da visão multifacetada da legitimidade organizacional, com processo construído e negociado na interação. Menciona-se ainda que os aspectos de legitimidade emergentes identificados estão associados à figura de um controlador externo, à dimensão de uniformização processual e de estrutura organizacional, à dimensão relacional, ao fomento da independência e regular funcionamento das funções que compõe os TCs e à transparência institucional e dos atos de controle externo, de modo a sinalizar para uma discussão sobre a problematização e, ao mesmo tempo, composição da legitimidade em torno dos TCs. 
Dessa forma, o percurso construído, a partir da utilização dos legitimacy acocunts enquanto recurso metodológico de análise (Elsbach 1994; Sheridan \& Mote, 2017), demonstraram que o debate e os posicionamentos dos atores caminharam para o reforço do componente processual (Machado-daSilva et al., 2006) e multidimensional ligado à legitimidade dos TCs. Sob a primeira ótica, relacionada ao componente processual, observou-se que, ao longo dos anos, a tônica do debate realizado foi alterada, de um processo de crise, para um reforço argumentativo voltado para a necessidade de aperfeiçoamento dessas organizações. Tal desenho conformou entendimentos sobre a natureza dos TCs e estabeleceu, sobretudo, papéis estratégicos nesse contexto, como foi o caso das corporações profissionais, que alternaram de um papel de estrito fomento recreacional para uma atuação estratégica e de produção de significados frente ao campo.

Já o segundo olhar, associado a multidimensionalidade da legitimidade dos TCs, foi marcado pela emersão, ao longo do tempo, de flancos de questionamento e produção de sentido sobre a legitimidade dos TCs, chamando a atenção para discussão de fatores organizacionais ligados a esse contexto. Assim, se no nível coletivo e de sociedade, a noção institucional de Justiça, ou controle como é o caso dos TCs, não está sob forte questionamento de legitimidade, no plano organizacional uma série de fatores como recursos organizacionais, isenção do decisor ou mesmo compliance organizacional, abre espaço para tais colocações, revelando um importante ponto de partida para estudos sobre legitimidade no contexto de organizações institucionalizadas, como é o caso das que compõe o contexto mais amplo de da Justiça.

\section{Conclusão}

O estudo teve como propósito investigar como legitimacy accounts conduzidos por diferentes categorias de atores, legais e não legais, manifestaram-se no debate acerca da reforma dos TCs brasileiros no período de 2000 a 2017. Nesse sentido, utilizou-se como fundamentação a noção processual de legitimidade organizacional, admitindo-se um foco na representação organizacional das instituições e na noção contestada, construída e negociada da legitimidade por meio da interação entre atores interessados.

Como resultados, com base no levantamento de legitimacy accounts, foi possível resgatar (a) os incidentes críticos de natureza cultural, política, econômica, legal, normativa e responsiva que, no período de 2000 e 2017, elaboraram os contornos do debate em torno da reforma dos TCs; (b) a centralidade das corporações profissionais, tanto na mediação e tradução do debate, quanto no desenho de estratégias de intervenção no campo organizacional e; (c) a identificação de aspectos emergentes associados à multidimensionalidade da legitimidade dos TCs, destacando-se dimensões de controle sobre o órgão e sobre o decisor, processual, organizacional, jurisdicional (das decisões), do decisor, relacional, responsiva e social.

Os resultados, portanto, reforçam o componente processual e multidimensional ligado ao debate e à legitimidade dos TCs, sendo a processualidade remetida pela alteração da compreensão do debate ao longo dos anos, de um espaço de crise para um locus de aperfeiçoamento organizacional e pela ressignificação de alguns papéis como o das corporações profissionais; e a multidimensionalidade reforçada pelo surgimento, ao longo do tempo, de espaços de questionamento e produção de sentidos sobre a legitimidade dos TCs em nível organizacional e ligados à recursos organizacionais, isenção do decisor ou mesmo compliance organizacional. Tal cenário sinaliza também para a importância do debate no contexto de organizações institucionalizadas, como é o caso das inseridas no contexto de Justiça.

Sob o ponto de vista empírico, observa-se também uma contribuição do estudo no sentido de aproximação da temática sobre o mundo prático, de forma que, a partir deste estudo, poder-se-ia, por exemplo, pensar a criação de ferramental para a operacionalização de observatórios de legitimidade em organizações da Justiça, de maneira a facilitar a captura do fenômeno ao longo do tempo e sua disseminação em linguagem acessível e gerenciável. No âmbito dos TCs, isso representaria uma maior 
aproximação de atores da sociedade em geral no tocante à realidade de inserção social dessas organizações no contexto de regras e condutas sociais aos quais estão submetidas.

Assim sendo, considerando as contribuições propostas neste estudo para as áreas de estudos organizacionais, administração pública e administração da Justiça, três possíveis extensões podem ser pensadas. A primeira extensão diz respeito à inserção da discussão sobre legitimidade no contexto de organizações institucionalizadas, como é o caso de algumas próximas do sistema de Justiça como os TCs. A segunda extensão sinaliza para a necessidade de melhor apreensão do fenômeno da legitimidade face a alguns aspectos específicos como: (a) a distinção entre instituições e organizações como objeto de legitimidade; (b) a exploração da natureza negociada e contestada da legitimidade organizacional e; (c) a possibilidade de operacionalização do conceito de legitimidade sobre organizações da Justiça a partir da sua multidimensionalidade. Por fim, a terceira extensão aponta para a questão da administração da Justiça, representada pelo esforço de compreensão voltado para aspectos organizacionais, interorganizacionais e institucionais que influenciam a noção de Justiça no contexto brasileiro.

Como limitações apresentadas pelo estudo, em primeiro lugar, menciona-se a delimitação temporal adotada, que trouxe um recorte delimitado em função dos acontecimentos em nível de campo, mas que poderia ser ampliada para, por exemplo, a partir da promulgação da Constituição Federal de 1988, espaço adicional que possibilitaria a captura do debate anterior à crise de legitimidade dos TCs nos anos 2000 no tocante às movimentações iniciais após ampliação dos poderes dessas organizações e com foco nas condicionantes geradoras da discussão. Outro fator limitante subjacente à análise realizada e que abre espaço para aperfeiçoamento é o desequilíbrio de vozes marcado pela predominância ligeiramente maior de determinado segmento considerado no campo, elemento que, muito embora tenha sido minimizado por triangulação de fontes e informantes e não represente o silenciamento absoluto de outros segmentos da sociedade como mídia, judiciário, academia e sociedade civil organizada, merece atenção em possível estudo futuro que busque capturar de forma ampliada ou de forma específica a participação de determinados atores, considerando o potencial de participação na reforma percebido neste estudo em função do movimento cada vez mais responsivo sobre debate, que tem incorporado e reconhecido demandas da sociedade ao logo do período analisado.

Por fim, como agenda para estudos futuros, recomenda-se a ampliação da noção de campo organizacional por meio da diversificação da amostra de atores envolvidos, ou mesmo a condução de investigações sobre atores específicos e a emergência de suas interações em nível de campo. Outro caminho sugerido seria a ampliação da delimitação temporal utilizada, uma vez que os TCs são organizações históricas. Chama-se a atenção ainda para a oportunidade de desenvolvimento de outros estudos, sob orientação qualitativa ou quantitativa, em que se tome a legitimidade como elemento central de análise, viabilizando dessa forma contribuições relacionadas à compreensão de suas diversas facetas.

\section{Nota}

\footnotetext{
${ }^{1}$ Versões preliminares do artigo foram apresentadas, em 2018, no European Group for Public Administration Annual Conference e no XLII EnANPAD, havendo, neste último, recebido prêmio de melhor trabalho da divisão de administração pública do evento.
}

\section{Referências}

Abraham, M. (2016). Os tribunais de contas e o poder cautelar de indisponibilidade de bens. Recuperado de https://www.jota.info/opiniao-e-analise/colunas/coluna-fiscal/coluna-fiscal-ostribunais-de-contas-e-o-poder-cautelar-de-indisponibilidade-de-bens-06102016

Agra, W. M. (2005). A reconstrução da legitimidade do Supremo Tribunal Federal: Densificação da 
jurisdição constitucional brasileira. Rio de Janeiro: Forense.

Akiyama, T. G. C., Almeida, V. E., Godri, L., \& Guarido Filho, E. R. (2015). Organizações e ambiente legal: A construção do sistema de identificação civil brasileiro. Revista de Administração Mackenzie, 16(6), 94-125. http://doi.org/10.1590/1678-69712015/administracao.v16n6p94-125

Akutsu, L., \& Guimarães, T. A. (2015). Governança judicial: Proposta de modelo teórico-metodológico. Revista de Administração Pública, 49(4), 937-958. http://doi.org/10.1590/0034-7612116774

Araújo, P. (2017, setembro 14). STF determina afastamento de 5 conselheiros do TCE-MT citados por ex-governador em delação. Recuperado de https://g1.globo.com/mato-grosso/noticia/stfdetermina-afastamento-de-5-conselheiros-do-tce-mt-citados-por-ex-governador-emdelacao.ghtml

Ashforth, B. E., \& Gibbs, B. W. (1990). The double-edge of organizational legitimation. Organization Science, 1(2), 177-194. https://doi.org/10.1287/orsc.1.2.177

Associação dos Membros dos Tribunais de Contas do Brasil. (2017b). A Atricom no Legislativo e no Judiciário. Revista Atricon, 7-10. Recuperado de http://www.atricon.org.br/wpcontent/uploads/2017/11/PDF_REVISTA-ATRICON_2017.pdf

Associação dos Membros dos Tribunais de Contas do Brasil. (2017a). Qualidade e agilidade dos Tribunais de Contas: Diretrizes e marco de medição de desempenho. Brasília: Autor.

Associação Nacional dos Auditores de Controle Externo dos Tribunais de Contas do Brasil. (2017, junho 9). Audiência pública extraordinária PARTE 1: Sessão: Comissão de constituição e justiça e de cidadania - realizada em 7 de junho de 2017. Recuperado de https://www.youtube.com/watch?v=XbaMTS09Rr8

Azevedo, R. R., \& Lino, A. F. (2018). O distanciamento entre as normas de auditoria e as práticas nos Tribunais de Contas. Sociedade, Contabilidade $e$ Gestão, 13(2), 9-27. https://doi.org/10.21446/scg_ufrj.v13i2.13665

Bardin, L. (2011). Análise de conteúdo. São Paulo: Edições 70.

Berger, J., Ridgeway, C. L., Fisek, M. H., \& Norman, R. Z. (1998). The legitimation and delegitimation of power and prestige orders. American Sociological Review, 63(3), 379-405. Retrieved from http://www.jstor.org/stable/2657555. https://doi.org/10.2307/2657555

Bolonha, C., Vasconcelos, D. de P., \& Mattos, K. D. G. de. (2017). A reputação do Judiciário brasileiro: Desafios na construção de uma identidade institucional. Revista da Faculdadde de Direito UFMG, 71, 69-101. https://doi.org/10.12818/P.0304-2340.2017v71p69

Bourdieu, P. (2014). Sobre o estado. São Paulo: Companhia das Letras.

Bybee, K. J., \& Narasimhan, A. G. (2015). Courts and judges: The legitimacy imperative and the importance of appearances. In A. Sarat \& P. Ewick (Eds), The handbook of law and society (pp. 118-133). West Sussex: Wiley Blackwell.

Carvalho, M. (2008). Simulando por meio da dinâmica de sistemas a influência dos tribunais de Contas estaduais na qualidade da gestão pública e na atração de investimentos privados. Cadernos EBAPE.BR, 6(1), 1-16. http://doi.org/10.1590/S1679-39512008000100008

Clark, T. S. (2009). The separation of powers, court-curbing and judicial legitimacy. American Journal of Political Science, 53(4), 971-989. http://doi.org/10.1111/j.1540-5907.2011.00554

Consultor Jurídico. (2017, abril 11). Em manifesto, docentes cobram mudanças em modelo de tribunais de Contas. Revista Consultor Jurídico. Recuperado de https://www.conjur.com.br/2017-abr- 
11/professores-assinam-manifesto-modelo-tribunais-contas

Conti, J. M. (2016, julho 26). "PEC do padrão mínimo" vai aperfeiçoar tribunais de contas. Revista Consultor Jurídico. Recuperado de https://www.conjur.com.br/2016-jul-26/contas-vista-pecpadrao-minimo-aperfeicoar-tribunais-contas

Conti, J. M. (2017, abril 4). Moralização da administração pública: Chegou a vez dos tribunais de Contas. Revista Consultor Jurídico. Recuperado de https://www.conjur.com.br/2017-abr04/contas-vista-moralizacao-administracao-publica-vez-tribunais-contas

Creed, W. E. D., Maureen, A. S., \& Austin, J. R. (2002). Clothes make the person? The tailoring of legitimating accounts and the social construction of identify. Organization Science, 13(5), 475496. https://doi.org/10.1287/orsc.13.5.475.7814

Creswell, J. W. (2007). Qualitative inquiry and research design: Choosing among five traditions (2nd ed.). Thousand Oaks: CA: Sage.

DiMaggio, P. J., \& Powell, W. W. (1991). Introduction. In W. W. Powell \& P. J. DiMaggio (Eds.), The new institutionalism in organizational analysis (pp. 1-38). Chicago: The University of Chicago Press.

Diniz, A. C. A. (2005). Teoria da legitimidade do direito e do estado: Uma abordagem moderna e pósmoderna. São Paulo: Landy.

Elsbach, K. D. (1994). Managing organizational legitimacy in the california cattle industry: The construction and effectiveness of verbal accounts. Administrative Science Quarterly, 39(1), 5788. https://doi.org/10.2307/2393494

Federação Nacional das Entidades dos Servidores dos Tribunais de Contas do Brasil. (2017, outubro). independência da função de auditoria de controle externo: É peciso assegurar o caráter técnico dos Tribunais de Contas. Revista FENASTC, (2), 4-13. Recuperado de http://online.fliphtml5.com/inhk/qmbg/

Fix-Fierro, H. (2003). Introduction: Why court efficiency? In H. Fix-Fierro, Courts, justice and efficiency: A socio-legal study of economic rationality in adjudication (pp. 1-11). Oxford and Portland, Oregon: Hart Publishing.

Friedland, R., \& Alford, R. R. (1991). Bringing society back in: Symbols, practices and institutional contradictions. In W. W. Powell \& P. J. DiMaggio (Eds.), The new institutionalism in organizational analysis (pp. 232-263). Chicago: The University of Chicago.

Friedman, L. W. (2016). Impact: How law affects behavior. Cambridge: Harvard University Press.

G1. (2017, março 29). Operação quinto do ouro nasceu de delações. Recuperado de https://g1.globo.com/rio-de-janeiro/noticia/operacao-quinto-do-ouro-nasceu-de-delacao-de-exdiretor-da-odebrecht.ghtml

G1 CE. (2017a, agosto 8). Assembleia Legislativa do Ceará aprova extinção do Tribunal de Contas dos Municípios. Recuperado de https://g1.globo.com/ceara/noticia/assembleia-legislativa-do-cearaaprova-extincao-do-tribunal-de-contas-dos-municipios.ghtml

G1 CE. (2017b, outubro 26). STF mantém extinção do Tribunal de Contas dos Municípios do Ceará. Recuperado de https://g1.globo.com/ceara/noticia/stf-mantem-extincao-do-tribunal-de-contasdos-municipios-do-ceara.ghtml

Gibson, J. L., \& Caldeira, G. A. (2009). Confirmation politics and the legitimacy of the U.S. supreme court: Institutional loyalty, positivity bias, and the alito nomination. American Journal of Political Science, 53(1), 139-155. http://doi.org/10.1111/j.1540-5907.2008.00362 
Gibson, J. L., Caldeira, G. A., \& Baird, V. A. (1998). On the legitimacy of national high courts. The American Political Science Review, 92(2), 343-358. http://doi.org/10.2307/2585668

Gibson, J. L., Lodge, M., \& Woodson, B. (2014). Losing, but accepting: Legitimacy, positivity theory, and the symbols of judicial authority. Law and Society Review, 48(4). http://doi.org/10.1111/lasr.12104

Gibson, J. L., \& Nelson, M. J. (2015). Is the U.S. supreme court's legitimacy grounded in performance satisfaction and ideology? American Journal of Political Science, 59(1), 162-174. http://doi.org/10.1111/ajps.12107

Greenwood, R., Oliver, C., Sahlin, K., \& Suddaby, R. (Eds.), (2008). The SAGE Handbook of organizational institutionalism. London, Thousand Oaks, New Delhi, Far East Square: Sage Publications. Retrieved from http://doi.org/10.1017/CBO9781107415324.004

Guarido, F., Guarido Filho, E. R., \& Eberle, V. (2017). Pregão eletrônico como mito racional: Análise dos processos licitatórios do Banco do Brasil. Desenvolvimento em Questão, 15(41), 233-274. https://doi.org/10.21527/2237-6453.2017.41.233-274

Guarido Filho, E. R., Luz, B. B. C., \& Silveira, T. R. (2018, abril). Legitimidade organizacional no contexto de organizações da justiça. In Anais do Encontro de Administração da Justiça, Brasília, DF, Brasil.

Guimaraes, T. A., Gomes, A. O., \& Guarido Filho, E. R. (2018). Administration of justice: an emerging research field. RAUSP Management Journal. https://doi.org/https://doi.org/10.1108/RAUSP-042018-010

IBOPE. (2016, agosto 3). Para brasileiros, Tribunais de contas são essenciais no combate à corrupção $e$ à ineficiência, revela pesquisa Ibope/CNI. Recuperado em 24 de abril, 2017, de http://www.atricon.org.br/imprensa/para-brasileiros-tribunais-de-contas-sao-essenciais-nocombate-a-corrupcao-e-a-ineficiencia-revela-pesquisa-ibopecni/

Johnson, C., Dowd, T. J., \& Ridgeway, C. L. (2006). Legitimacy as a social process. Annual Review of Sociology, 32(1), 53-78. http://doi.org/10.1146/annurev.soc.32.061604.123101

Kagan, R. A. (2009). Introduction to the transaction edition. In P. Nonet \& P. Selznick, Law and society in transition:Toward a responsive law (2nd ed. pp. vii-xxvi). New Jersey: Transaction Publishers.

Kluttz, D. N., \& Fligstein, N. (2016). Varieties of sociological field theory. In S. Abrutyn (Ed.), Handbook of contemporary sociological theory (pp. 185-204.). New York: Springer.

Lamertz, K., \& Baum, J. A. C. (1998). The legitimacy of organizational downsizing in Canada: An analysis of explanatory media accounts. Canadian Journal of Administrative Sciences, 15(1), 93107. https://doi.org/10.1111/j.1936-4490.1998.tb00154.x

Laniado, R. N. (2000). Políticas públicas e desempenho institucional em relação à criminalidade. Organizações \& Sociedade, 7(17), 99-111. http://doi.org/10.1590/S1984-92302000000100007

Lino, A., \& Aquino, A. (2018). A diversidade dos Tribunais de Contas regionais na auditoria de governos. Revista Contabilidade \& Finanças, 29(76), 26-40. https://doi.org/https://doi.org/10.1590/1808-057x201803640

Lins, J., Neto (2000). Tribunal de Contas: Um desconhecido na República. Revista de Direito Administrativo, 219, 205-218. http://doi.org/10.12660/rda.v219.2000.47502

Loureiro, M. R., Teixeira, M. A. C., \& Moraes, T. C. (2009). Democratização e reforma do Estado: o desenvolvimento institucional dos tribunais de contas no Brasil recente. Revista de Administração Pública, 43(4), 739-772. https://doi.org/10.1590/S0034-76122009000400002 
Machado-da-Silva, C. L., Fonseca, V. S. da, \& Crubelatte, J. M. (2005). Estrutura, agência e interpretação: Elementos para uma abordagem recursiva do processo de institucionalização. Revista de Administração Contemporâea, 14(Edição Especial), 77-107. http://doi.org/10.1590/S1415-65552010000600005

Machado-da-Silva, C. L., Guarido Filho, E. R., \& Rossoni, L. (2006). Campos organizacionais: Seis diferentes leituras e a perspectiva de estruturação. Revista de Administração Contemporânea, 10 (Edição Especial), 159-196. https://doi.org/ 10.1590/S1415-65552006000500009

Mariano, C. M. (2010). Legitimidade do direito e do poder judiciário. Belo Horizonte: Del Rey.

MUDA TCE-RJ. (2017, dezembro 4). Lançamento da campanha MUDA TCE-RJ. Recuperado de https://www.youtube.com/watch?v=ph-IZvXOy4w

O Globo. (2017, março 30). Estados com problemas nos Tribunais de Contas. Recuperado de https://oglobo.globo.com/brasil/estados-com-problemas-nos-tribunais-de-contas-21134076

Oliveira, J. M. (2017). A inadiável e já atrasada reforma dos tribunais de Contas. Recuperado de https://www.conjur.com.br/2017-abr-11/inadiavel-atrasada-reforma-tribunais-contas

Oliveira, O. C. de (2008). Diante do princípio federativo, seria constitucional uma lei nacional de processo dos tribunais de contas? Revista do Tribunal de Contas da União, 40(113), 13-32.

Power, M. (2000). The audit society - Second thoughts. International Journal of Auditing, 4(1), 111119. https://doi.org/10.1111/1099-1123.00306

Ribeiro, L. M. L., \& Machado, I. S. (2014). Repressão, autonomia e responsividade: O direito que se exerce nas delegacias de polícia no Brasil. Sociedade e Estado, 29(1), 153-180. Recuperado de http://www.scielo.br/pdf/se/v29n1/09.pdf. https://doi.org/10.1590/S0102-69922014000100009

Rossoni, L. (2016). O que é legitimidade organizacional? Organizações \& Sociedade, 23(76), 110-129. https://doi.org/10.1590/1984-9230766

Sakai, J., \& Paiva, N. (2016). Quem são os conselheiros dos Tribunais de Contas. Transparência Brasil, 1-32. Recuperado de http://www.atricon.org.br/wpcontent/uploads/2014/04/TransparenciaBrasil_TribunaisdeContas_Abril2014.pdf

Saunders, M. N. K., Lewis, P., \& Thornill, A. (2009). Research methods for business students (Cap. 5, 5a ed.). Harlow, England: Pearson Education.

Scott, W. R. (2008). Institutions and organizations (3rd ed.). Thousand Oaks: Sage Publications.

Sheridan, M. J., \& Mote, J. E. (2017). Tracing legitimating accounts during times of change: The case of the organic food certification debate, 1990 to 2011. Organization \& Environment, 31(4), 360383. https://doi.org/10.1177/1086026617706697

Silva, L. P. (2017). Reforma ideal nos tribunais de Contas pede novas estruturas de controle. Recuperado de https://www.conjur.com.br/2017-set-03/lucieni-pereira-reforma-ideal-tribunais-contas

Suchman, M. C. (1995). Managing legitimacy: Strategic and institutional approaches. The Academy of Management Review, 20(3), 571-610. https://doi.org/10.2307/258788

Suddaby, R., Bitektine, A., \& Haack, P. (2017). Legitimacy. Academy of Management Annals, 11(1), 451-478. https://doi.org/10.5465/annals.2015.0101

Viana, I. (2017, abril 6). Tribunais de contas necessitam de aperfeiçoamento. Revista Consultor Jurídico. Recuperado de https://www.conjur.com.br/2017-abr-06/ismar-viana-tribunais-contasnecessitam-aperfeicoamento 
Willeman, M. M. (2017). Accountability democrática e o desenho institucional dos Tribunais de Contas do Brasil. Belo Horizonte: Fórum.

Yin, R. K. (2001). Estudo de caso: Planejamento e métodos (2a ed.). Porto Alegre: Bookman.

\author{
Autores \\ Bruno Batista de Carvalho Luz \\ UNB, Campus Darcy Ribeiro, Prédio da FACE, Asa Norte, Cep 70910-900, Brasília, DF, Brasil. \\ UFG, Rua Samambaia, s/n, Campus Samambaia, 74690-900, Goiânia, GO, Brasil \\ E-mail: brunobdcl@gmail.com \\ Marcos de Moraes Sousa \\ IFGOIANO, Rodovia Go-154, Km 03, s/n, Caixa Postal 51, Campus Ceres, 76300-000, Ceres, GO, Brasil \\ UFG, Rua Samambaia, s/n, Campus Samambaia, 74690-900, Goiânia, GO, Brasil \\ E-mail: marcos.moraes@ifgoiano.edu.br; lceara@hotmail.com \\ Edson Ronaldo Guarido Filho \\ UP, Rua Prof. Pedro Viriato Parigot de Souza, 5300, 81280-330, Curitiba, PR, Brasil \\ UFPR, Av. Prefeito Lothário Meissner, 632, Jardim Botânico, 80210-170, Curitiba, PR, Brasil \\ E-mail: edson.guarido@gmail.com

\section{Contribuições} \\ $1^{\circ}$ autor: Definição de pesquisa, desenvolvimento teórico e metodológico, redação e revisão final. \\ $2^{\circ}$ autor: Definição de pesquisa, desenvolvimento teórico e metodológico, redação e revisão final. \\ $3^{\circ}$ autor: Definição de pesquisa, desenvolvimento teórico e metodológico, redação e revisão final.
}

\title{
Financiamento
}

Os autores relataram que não houve suporte financeiro para pesquisa deste artigo.

\section{Conflito de Interesses}

Os autores afirmaram que não há conflito de interesses.

\section{Verificação de Plágio}

A RAC mantém a prática de submeter todos os documentos aprovados para publicação à verificação de plágio, mediante o emprego de ferramentas específicas, e.g.: iThenticate.

\section{Material Suplementar}

A base de dados da pesquisa não está disponibilizada publicamente em razão do contorno metodológico do estudo e do sigilo associado à maioria dos dados coletados, os quais envolvem autoridades ligadas ao contexto dos Tribunais de Contas. Interessados deverão entrar em contato com os autores por meio do endereço brunobdcl@gmail.com. 